Copyright (C) The Author(s), 2022. Published by Cambridge University Press on behalf of the Dance Studies Association. This is an Open Access article, distributed under the terms of the Creative Commons Attribution licence (https://creative commons.org/licenses/by/4.0/), which permits unrestricted re-use, distribution, and reproduction in any medium, provided the original work is properly cited.

doi:10.1017/S0149767721000346

\title{
Movement as Matter: A Practice-Based Inquiry into the Substance of Dancing
}

\author{
Alison D'Amato
}

\section{Introduction}

I

$\mathrm{n}$ the summer of 2011, I stood barefoot in the concrete courtyard outside of The Box Gallery in Los Angeles's Chinatown, sweating, knees bent, meeting the weight of bodies held aloft in Simone Forti's corporeal sculpture, Huddle. In the winter of 2015, I moved incrementally across the plush, gray carpet of a Hammer Museum gallery, working through a glacially slow, two-hour loop of choreography in Maria Hassabi's PLASTIC. In the spring of 2017, I got into the habit of dancing in my parched and dusty backyard, searching for an improvisational practice (later called The Sacred Something) that would induce a sense of parity between my cascading movement and the multitude of things around me: the hot pink bougainvillea, the rusty discarded screws, my watchful cat. At some point these dancing experiences started to coalesce into persistent questions about movement's materiality. I was not only concerned with the body's materiality-its flesh and sinews and bony anatomical signposts_-but that of movement, the "things," or even "objects," that might be understood to manifest in and from a body's dancing.

Sliding indiscriminately between the territories of materiality, movement, objects, and thingsI acknowledge at the outset that these questions hinge on an expanded notion of what counts as matter. Over the past two decades, theories about stuff have trained a number of discourses on material phenomena, reenergizing the seemingly abandoned philosophical pursuit of things-in-themselves. A partial list of these interconnected discourses includes speculative realisms, object-oriented ontologies, thing theory, actor-network theory, contemporary animisms and vitalisms, deep ecology, critical plant studies, posthumanisms, and-to borrow a phrase made popular by Jane Bennett (2010)_ “vibrant" materialism. It would be impossible to pinpoint a common stance across these fields, but it is reasonable to identify some collectively precipitating factors. Those associated with speculative realism, for example, rally against the post-structuralist viewpoints that dominated the late twentieth century and, as they see it, assiduously neglect the material world. ${ }^{1}$ Their work often follows Quentin Meillassoux in fixing the term "correlationist" to theoretical gestures reducing the world to epistemological or semiotic networks, human-centered webs robbing nonhuman (or even nonliving) entities of ontological depth (2008). Beyond questions about the primacy of theoretical models, though, are the pressing anxieties of the Anthropocene:

\footnotetext{
Alison D'Amato (adamato@usc.edu) is a researcher, choreographer, and performer based in Los Angeles, California. She is Assistant Professor of Practice at USC's Kaufman School of Dance and has also taught at UCLA and CalArts. She holds a PhD in Culture and Performance from UCLA, and an MA in Dance Theater Practice from Trinity Laban. Her writing on performance can be found in Choreographic Practices, SFMOMA's Open Space, Imagined Theatres, Contact Quarterly, and X-TRA Contemporary Art Quarterly.
} 
political and ethical distinctions between life and nonlife, the advances of biotechnology and genetic modification, the imbrication of the subject with the digital and the virtual, the hyperkineticism of capital, the ruthless virality of the contemporary pandemic, and an ever-escalating climate crisis.

Despite the multivocality of these discourses, they all, in some way, establish a more inclusive sense of the substantive, suggesting an expanded field wherein movement might assert a presence. In my exploration of materialist literatures, I encountered, for example, objects resisting fixity, objects prone to "unleash forces" against one another (Bryant, Srnicek, and Harman 2011, 22), unified exteriors belying internal multiplicity, linguistic objects, "hyper-communicative objects" (Santos-Granero 2009, 10), and "hyperobjects" so large as to resist quantification (Morton 2011, 165-168). If philosopher Levi Bryant, for example, grants objecthood to stuff "as diverse as mind, language, cultural and social entities," (2011, 18-19), why not stuff like movement? Certainly, my flesh is substantive, but so is the arc of my arm as it glides from here to there, so is the slow slide along the smooth wood of a studio floor bringing my head flush with the wall, so are the impulses, memories, and decisions that rise in me as I move. Engaging with accounts of the material world that contest its inertness, I realized that, by extension, I was being offered the opportunity to realign movement with it.

Although these initiatives have stimulated a healthy level of cross-disciplinary dialogue, they remain under-acknowledged with respect to dance, typically associated as it is with ephemerality and thus implicitly excluded from considerations of the material. ${ }^{2}$ Anxieties regarding dance's putative ephemerality can be discerned at least as far back as the sixteenth century, when dance manuals began to consolidate movement for commodified transmission and exchange. ${ }^{3}$ Scholarship of the past several decades profoundly complicates the question of performance's relationship to disappearance, however, proposing notions such as a bodily "will to archive," efficacious cultural "repertoires," and the meaningful "traces, glimmers, residues, and specks of things" that are found in bodies, collective memories, notational documents, and the like. ${ }^{4}$ In an influential treatment of the "cross-temporalities" of reenactment, Rebecca Schneider focuses on performance's "remains," where doing serves as a valid means of archiving, and documentation serves as a potent manifestation of theatricality (2011). Schneider troubles the association of liveness with disappearance, elucidating "the ways in which the live is not only vulnerable to suspension, but the very material of arrest" (142). Linking performance's materiality to the complicated temporalities evident in all manner of redoings, Schneider offers a persuasive antidote to the assumption that what passes away is gone.

Nearly twenty years prior to Schneider's work on reenactment, Mark Franko addressed the reconstruction of baroque dance, suggesting that such pursuits might be best oriented toward the "replication" of sociocultural effects rather than the reanimation of physical forms ([1993] 2015, 135). Franko's emphasis on construction (rather than reconstruction) underscores the past's generative potential, focusing on what materializes rather than what gets lost. Franko continued to develop his position on choreographic reenactment in a 2017 anthology, proclaiming the "death of ephemerality" and pointing to an early twenty-first-century movement toward the "post-ephemeral" $(2017,7)$. Like Schneider, Franko offers crucial insight into the complicated inter-temporalities at play in performances that limn past, present, and future. I wonder if, at the horizon of the postephemeral, we might find not only new temporalities but also new materialities? And in what ways might these materialities be asking for disentanglement from the blurry boundaries between past/ present and presence/absence? As I wrote in the score for The Sacred Something: "Dance only looks more ephemeral than other kinds of objects from a very anthropomorphic perspective on time" (D'Amato 2019). Indeed, the striking theoretical expansion of materiality (along with a concomitant decentering of the human experience) encouraged me to accord the things erupting from my dancing autonomy, unhitched from my own-or anyone's-experience of them passing away.

In probing the contours of these movement landscapes, however, I concede the paradox that my descriptive language centers me as an authoritative witness. Indeed, my accounts resemble 
phenomenological description insofar as they follow from detailed, subjective explorations of movement "phenomena." Yet, much of the literature I have mentioned repudiates phenomenology. Targeted by Meillassoux as a primary engine of correlationism, phenomenology implicitly rejects the notion "that it is possible to consider the realms of subjectivity and objectivity independently of one another," thereby establishing the "primacy of the relation over the related terms" (Meillassoux 2008, 5). I cannot resolve this contraction, except to note that my analysis is not oriented to bounce "backwards toward an elucidation of the structures of consciousness" (Sheets-Johnstone 2015, 9). I burrow into my memories of these dances, perhaps quixotically, in order to decenter subjecthood, suggesting the ways in which the dances enact, desire, and circulate independently of any particular body associated with them. In the case of Huddle, I arrive at its curious status as a choreographic assemblage under the stewardship-though not quite ownership—of New York's Museum of Modern Art (MoMA). In the case of PLASTIC, I query its movement's tendency to "withdraw," demolishing the "primacy of the relation" and raising the unsettling possibility that the spectator's proximity may not guarantee an experience of perceptual access (Meillassoux 2008, 5). In The Sacred Something, I go as far as possible into the paradoxical territory of decentering myself, focusing on a corporeal experience of "overwhelm" in which things inside, outside, and coming through my body exceed my capacity to take stock of them.

Although I lean on materialist perspectives, my goal is not to catalogue those perspectives and correlate them to danced embodiment, nor is it to justify the soundness of any particular approach. I am not proposing a revised ontology, replacing tropes about dance's constitutive ephemerality with those reifying an essential materiality. Likewise, exploring movement's materiality does not mean affirming the preeminence of movement within dance's ontological framework: it is not an affirmation of the kinetic (whether substantive or not) as an ontological bedrock. As so much contemporary choreographic work continues to decenter kinetics in favor of conceptual or political propositions, linguistic play, unconventional performer-spectator relationships, and extreme states of consciousness, artists make it clear that movement is not the only stuff in question. ${ }^{5}$ However, as part of the ongoing conversation about what dance can be made of and what it can do, thinking movement beyond evanescence can only enrich the vocabularies at our disposal. Indeed, movement might be woven into a web of associated materialities, including somatic, expressive, and laboring bodies, the material conditions through which bodies move, and dances configured as entities and, sometimes, commodities. ${ }^{6}$ It is from within that nexus of entanglements that I glimpse the way in which movement's mattering could contribute to a renewed ethics for performance in a precipitously changing world, one that does not fix the human experience at its center. Discussing the relevance of new materialist perspectives to the "toxified worlds" engendered by settler colonialism, Elizabeth Povinelli encourages us to remember that

the world of objects and subjects is not flat. It must be viewed from the unequal forces redrawing and demanding certain formations as the condition for an object's endurance, extension, and domination of interest. This is not to make humans the center of the object-assemblage world, nor to make other things passive. Rather it is to make the forces that produce centers and passivities the name of the game. $(2016,91)$

In the analysis that follows, I endeavor to illuminate the ways in which these dances assert themselves, entwined inextricably in my experience of them while nonetheless enduring and extending beyond me, generating centers and passivities all their own.

\section{The Ongoing Intra-Activity of Huddle}

Taking the long view of Huddle across a sixty-year life span, it is possible to discern a very particular choreographic materiality: one that is hypermalleable and surprisingly durable all at once. Lasting about ten minutes, the dance is a terse choreographic statement, and any iteration of it relatively 


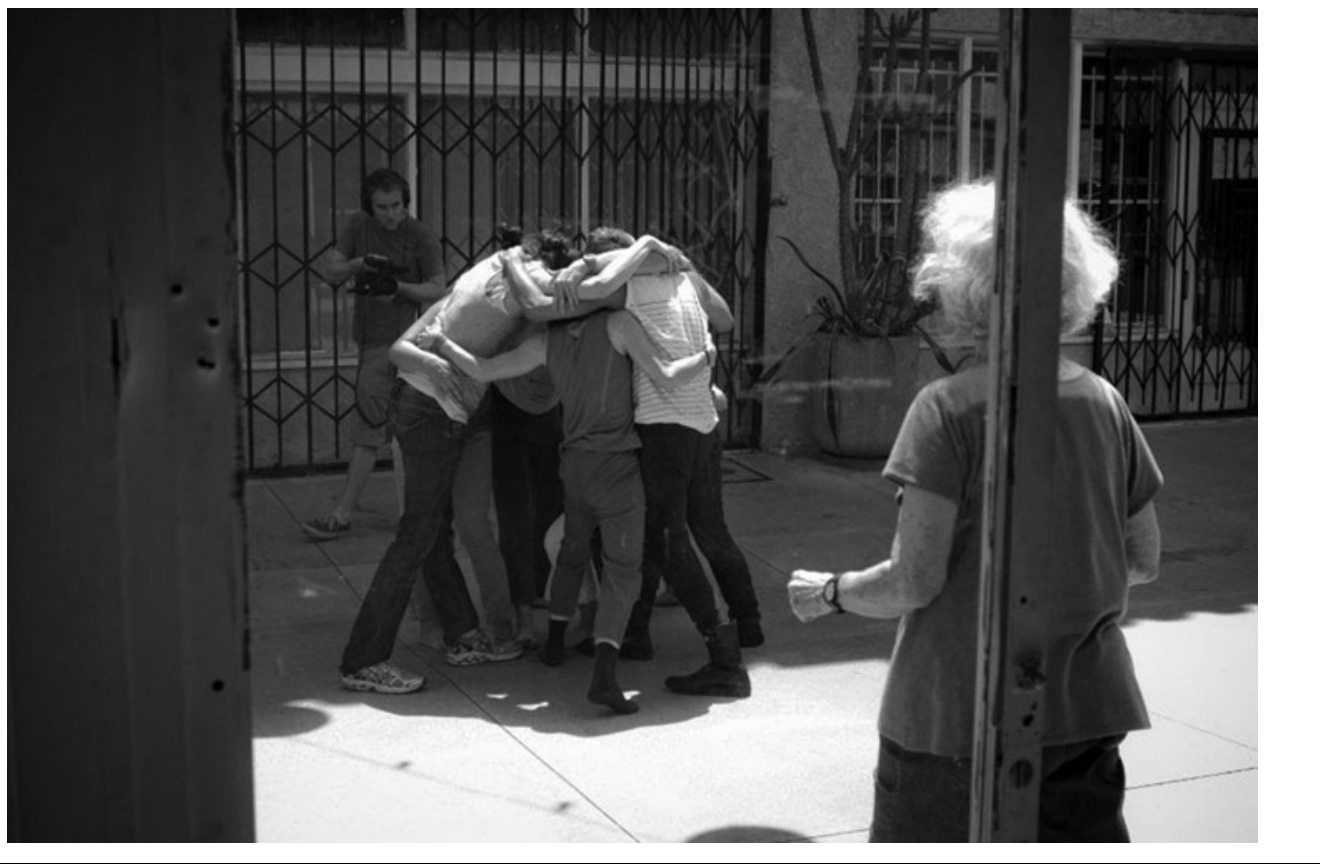

Photo 1. Simone Forti watching Huddle ([1961], 2011) outside The Box Gallery. Photo by Nguyễn Nguyên, courtesy of the photographer.

fleeting. Nonetheless, it has been performed for decades in professional and pedagogical settings, evincing surprising staying power. It has been richly documented and extensively analyzed, more so in recent years, since the overdue acknowledgement of Forti's role in early minimalism and conceptual art (Spivey 2009). My own account of Huddle listens closely to what the unique life span of Forti's "dance construction" has to tell us about its kinetic objecthood, one defined by a proclivity for self-containment that does not foreclose fluidity and proliferation. To understand this fundamental tension, it is necessary to look not only at its kinetic substance but also at how those simple movements express nonhuman agency in their geographic and temporal drift. As with all three case studies, my argument does not revolve around the notion that Huddle represents a particularly "materialist" approach to choreography or performance (though one could certainly make that argument); rather, I argue that the dance itself invites a critical framework grounded in a notion of materiality capacious enough to accommodate its multifaceted presencing.

Very simply, Huddle revels in the act of climbing. The dance demands a specific kind of climb-not just up, but up and over. Performers in the huddle, whether climber or part of the base, are part of a mass of tumbling physicality, constantly shifting to support the work's central action. To begin Huddle, a group of dancers enters a designated space, sometimes taking off their shoes. The huddle forms without predetermined plans for performer placement and arrangement of limbs. Knees are bent, backs are hunched, heads are bowed. From inside, performers hear, see, and feel one another breathing. There might be some giggling, imperceptible from the outside. Someone likely wears a watch to cue the group to the dance's duration. Deciding it is time to climb, a performer might worry about her bulk, cringing as she hoists her heaviest parts (mass of pelvis and belly) onto a set of shoulders that feel startlingly delicate and winglike. But they hold; the structure holds. The climber finds a crook for the heel or the knee, gains some ground, and then reaches a tipping point. She is headed down the other side. The ten minutes of the dance's duration aspire toward continuity, a whole both with and without differentiating parts. Near the end of ten minutes, the wristwatch strategically hidden within the mound quietly buzzes. The huddle disbands, performers put their shoes back on, and Huddle is done. 
Huddle was born from Forti's desire to invest in a relatively pedestrian action and to present that action to the spectator in choreographic isolation. Despite the complexity of inevitable performer variation, Forti rigorously pursues compositional unity via the simplicity of the choreographic imperative and the prohibition of performer adornment. ${ }^{7}$ Accordingly, Forti describes Huddle as an exploration of "continuous action" or "steady state" (Forti 1991, 7; Leung 2018). Her desire to isolate simple movement ideas connects to the post-Cagean discourse of Forti's early 1960s contemporaries, articulated most vehemently by the composer La Monte Young. Where John Cage had pursued anarchic inclusion, puncturing the protective skin of a composition to allow the world in, Young strained in the opposite direction, looking for anarchy under the surface of something ostensibly unified, deploying extended duration to "get inside of a sound" (Young 1965, 81). What was to be found inside a single, long-duration sound was, for Young, "parts and motions": not unlike the disunified singularity borne out by the mass of dancers in Forti's Huddle (81) or the disunified singularity evoked by philosopher Levi Bryant's assertion that "every object is a crowd" $(2011,28)$.

Despite (or perhaps because of) Huddle's simplicity, its early presentation was twofold: around the time that two huddles were performed in Young's concert series at Yoko Ono's Chamber Street loft, Forti also contributed texts, including a description of Huddle, to a sprawling publication coedited by Young and Jackson Mac Low, titled An Anthology. ${ }^{8}$ Forti's inclusion signals her immersion in the proto-Fluxus culture wherein compositions often took the form of brief text scores, a format designed with distribution and circulation in mind. Not only does the long corporeal history of Huddle extend the dance's life, but so, too, does its early appearance as a language score suggest that Forti always envisioned the dance as something to move, shift, and engage distant readerships. As Meredith Morse points out, the existence of Forti's An Anthology writings produces a temporal multiplicity in which the "site and time of a work's production oscillates between textual presentation (here and now) and possible actualization (where and how?)" (2016, 79). Huddle's early double life signals its close proximity to emergent forms of conceptual art, where works might be said to manifest in the imaginations of readers. I contend, though, that Huddle's extension from the physical to the conceptual does not so much constitute a dematerialization as it nuances and specifies the dance's distinctive material contours.

Long after its first appearances in performance and in text, Huddle's acquisition by MoMA (along with several of Forti's other works choreographed between 1960 and 1961) indicates a great deal about the material conditions that the dance demands for itself. Art historian Megan Metcalf details a six-year-long trajectory of discussion and logistics culminating in the 2015 purchase, pinpointing the "minimal, straightforward qualities" that, in addition to their status as harbingers of conceptualism and minimalism, make Forti's early works compelling candidates for museum acquisition. She goes on to write, however, that Huddle "strained the museum's definition and purpose," particularly with respect to the dance's liveness, its intimacy, and its tendency to scramble "hierarchies between objects and people, artwork and audience" (Metcalf 2018, 148-149). Metcalf's analysis demonstrates how Forti's works required a multimodal curatorial approach, incorporating drawings, photographs, teaching videos, artist statements, and other materials geared toward documentation and reperformance. ${ }^{9}$ Although the complexity of this conservation apparatus contrasts sharply with those typically deployed to preserve objects that can be trusted to stay much more still than Huddle, it nonetheless suggests a difference in degree rather than kind. All things eventually degrade, after all, despite institutional efforts to stave off that degradation.

It certainly seems possible to interpret the institutionalization of Huddle as the yielding of something inherently corporeal and time-based to a logic of disembodied preservation and fixation. It is also possible, however, to see the details of this acquisition as expressive of Huddle's agencya nonhuman form of enactment and an assertion of its way of "mattering" in the world. In theoretical physicist and feminist theorist Karen Barad's revision of the term, "agency" is "cut loose from its traditional humanist orbit," no longer "aligned with human intentionality or subjectivity" but reoriented toward "intra-activity." (2007, 235). If the simple movements of Huddle possess this 
capacity for agency, then they subtly dislocate concerns about whether museum acquisition represents an appropriate fate for the dance. Instead, we might ask: Is the apparatus of the acquisition aligned with the dance's agential tendencies? Does the museum account not only for the specificity of its steady-state action but also for its propensity to drift, proliferate, and infiltrate new bodies? Indeed, this seems to be the case, as is evidenced in the "unusual arrangement that permits the work's ongoing life in the world beyond the supervision of the museum" (Metcalf 2018, 255). Indeed, MoMA is charged with maintaining the dance's integrity even as it moves about the world freely; prospective performers are perfectly within their rights to enact Huddle without the institution's permission.

To bridge the gap between the museum's conservation apparatus and the inherently bodied nature of Forti's works, MoMA collaborated with a well-known performance institution, Danspace Project, to host a weeklong research residency in late 2016. Forti was present in order to facilitate the "body-to-body transmission" that would allow the works to continue to "inhabit the dance community" (Stuart Comer as cited in Lim, 2016). Interestingly, performer accounts of the residency teem with descriptions emphasizing Huddle's materiality. Lauren Bakst notes, for example, that "if I blur my focus, I see an organism in an ongoing process of expanding its shape and returning, expanding and returning" (2017). Molly Lieber reflects on Forti's presence: "I felt safe in her assuredness... . I knew it would work, because the dance has been happening for so long. So really it felt like the dance didn't depend on me doing it at all, but that it had already been happening and I was just stepping into it for a moment and feeling it" (2017). Comer, Bakst, and Lieber all underscore Huddle's capacity for substantive, extra-human, agency: its ability to "inhabit" the dance community, its status as an "organism" undertaking an "ongoing process," and its "independence" from the dancers performing it.

Even as the MoMA/Danspace process underscores Huddle's tendency toward dynamic "intraactivity," the uptick in recent museum acquisitions (not limited to Forti's) certainly raises questions about the transformation of performance into something stable enough to enter the realm of museum collection. Like Forti, Hassabi has found eager audiences in museum and gallery spaces; similarly, both of these artists explicitly relate the dances I've mentioned to conventions related to the display of objects. Long before its landmark acquisition, scholarship addressing Huddle emphasized the work's affinity with sculpture. ${ }^{10}$ And much of Hassabi's work, including PLASTIC, has been contextualized as an exploration of the body's sculptural potential. ${ }^{11}$ My own movementbased inquiries also began in dialogue with a visual artist; the aforementioned backyard improvisation had originally been embedded in an otherwise tightly choreographed work wherein dancers navigated a landscape of purpose-built objects. I believe, though, that these movement experiences offer more varied possibilities for co-thinking dance and materiality than their proximity to visual art practices (and economies) might immediately suggest. I do want to acknowledge the complicated politics of dance's objectification via modes of museum acquisition and display, but I also want to illuminate how dances can materialize via trajectories that are not always circumscribed by art institutional parameters. That is, I want to speculate about the nature of their materiality before assuming that absorbing movement-based works into object-centric cultures necessarily involves subordination to a logic that is inherently opposed to them. In the case of PLASTIC, this means reflecting on the conditions of display that render things-including movements and the people who perform them-perceptually "available" to museum audiences.

\section{Withdrawal and Relational Dissonance in PLASTIC}

Whereas Forti's Huddle shifts and tumbles, Hassabi's choreography in PLASTIC feels blocklike, stringently set, and near-static: the former a dance-thing with rough edges and perpetually morphing irregularities; the latter smoothly serene, impervious to the world around it. Unlike Forti, Hassabi explores the body's sculptural potential through radical deceleration rather than in the 


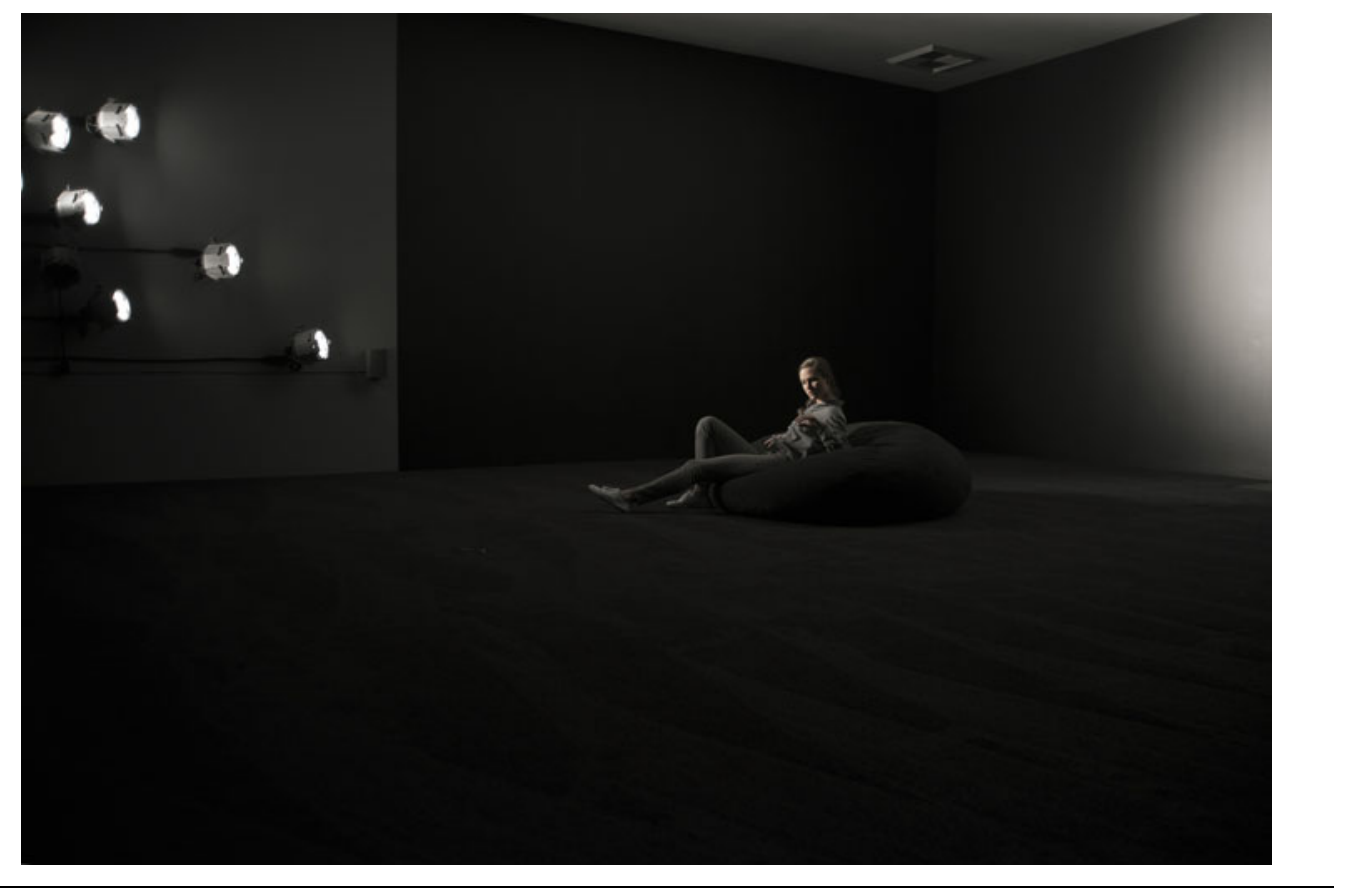

Photo 2. Hammer Projects: Maria Hassabi, January 31 - March 1, 2015. Installation at the Hammer Museum, Los Angeles. Photo by Thomas Poravas.

application of continuous action. While both dances conflate the corporeal and the sculptural, each promotes-from my perspective within these movement worlds-subtly different currents of relational charge between performer and spectator. In his analysis of Huddle, André Lepecki highlights an early performance that Forti staged behind audience members absorbed in another of the dance constructions. Lepecki dwells on this huddle lurking mischievously beyond the audience's gaze in order to evoke the potency of the "barely perceptible," deeming it a "thingly dance" refusing to coalesce under an audience's scrutinizing gaze (2016, 34-35). When I danced Huddle in 2011, however, I felt its movement to be the target of focused audience attention. It was the experience of performing Hassabi's PLASTIC, by contrast, that placed me on a knife's edge between perceptibility and imperceptibility. Creeping through PLASTIC's radically slow movement landscape, I registered a surprising sense of confrontation between my body and those looking. If Huddle's materiality evidences a tension between self-containment and proliferation, then PLASTIC stages an unfolding drama between the performing body's perceptual availability and its capacity to withhold.

In the iteration of PLASTIC that I performed at the Hammer Museum in 2015, the choreography consisted of two hours of material requiring extreme physical control, movement so slow that it barely registered as such. This included static poses held for durations lasting between thirty seconds and five minutes, intercut by shifts unfolding at just a temporal notch above stillness. I was engaged, like all the dancers in Hassabi's Los Angeles-based case, in a section of the work that occupied a ground floor gallery; outside the gallery, Hassabi and a New York-based group activated the museum's public spaces, performing for intent observers as well as those simply passing by. The New York dancers had been working with Hassabi prior to arriving, but the Los Angeles group learned the choreography quickly, often practicing short sequences of the solo material in unison. Once we had learned the material, it was extraordinarily difficult to rehearse it as a solo-working the loop one by one would have been unmanageably time-consuming. So it was that I found myself in the gallery, getting used to the experience of dancing the work's entirety at nearly the same moment that I was acclimating myself to dancing it for spectators. 
The museum had designated a nearby conference room for the cast of PLASTIC to get dressed, stretch, eat, or relax. Wearing light-gray denim and white sneakers, I left that room at the appointed time each day and walked directly toward the gallery, readying myself for the work's physical and mental demands. Covering this short distance, I noticed a consistent process of drawing inward, attending more closely to my still-pedestrian kinetics while detaching from the world around me. Once inside, I began counting almost immediately, setting the internal metronome that I, and I alone, would maintain for the next two hours. Learning PLASTIC meant getting comfortable working hard while seeming to do very little, an experience alternately empowering and excruciating. On the one hand, I told myself, the rigors of this choreography should be enough for the spectator, offering myself up, as it were, for viewing at any angle and any duration, accepting being seen at close range while doing what appeared to be very little. On the other, my body rioted, fighting the urge not to be precisely where I was at any given moment. This was a result not only of my deep habituation to the quickness of everyday life (especially wired, as we now are, to the constant information streams borne by our devices) but also of the trained performer's powerfully internalized urge to earn and command spectator attention.

It did not take long to realize that I was going to be alone for enormous stretches of time. Abiding in these lengths of solitude, enacting a sequence of movements that allowed no "marking" or shortcuts, it was all the more intense when museum visitors would crack open the door and step in. Depending on where I was in the work's progression, spectators were greeted with varying degrees of illumination established by a cluster of stage lights-on their own two-hour trajectory between fully extinguished to blindingly brilliant-installed in a corner of the gallery opposite the door. In either case, the majority of spectators seemed not to expect a performing body, and the conditions of the light often obscured my presence. It was common to witness visitors rush into the gallery, exclaim something about its brightness (or darkness), cast a glance around the room or take a few steps further in, and then rush out in the space of fifteen to twenty seconds, a duration I can confidently assert because I was always counting. If the room was in peak darkness, I often sensed that visitors had not seen me. Sometimes, they seemed to see me but not grasp that I was performing. Even more frequently, I registered that visitors were actively disturbed by my presence-they saw me but struggled to negotiate the task of looking. Although they could position themselves in the gallery wherever they liked, and could certainly avert my carefully choreographed gaze, the sealed gallery space pressurized our relationship, unquestionably drawing visitors into the performance. While dancing, I thought often of Michael Fried's rallying cry against the theatricality of minimalist sculpture, his repudiation of the objects that, in their brutal simplicity, enlist the viewer in a drama. Like these sculptures, I was, to borrow Fried's words, not just in the space of the observer, but rather "in his way" $(1998,154)$. As one of Hassabi's minimalist corporeal sculptures, I teetered between subjecthood and objecthood, caught in a vertiginous territory that seemed challenging for the spectator to digest, or even endure.

Although I can only speculate on the nature of individual spectator experience, I can attest to the way in which Hassabi's choreography made relationality a dominant focus of my own attention. In fact, analyses of Hassabi's work frequently dwell on the tension between its characteristic slowness and audience reaction. ${ }^{12}$ Treating a subsequent iteration of PLASTIC at MoMA, Claire Bishop uses Hassabi's work to counter angry assertions concerning the increased prevalence of performance in museums. Critics levelling this charge (among them Jerry Saltz and Sven Lütticken) see performance as a gambit to accommodate shrinking attention spans, offering little but fodder for a ceaseless social media grind. Bishop certainly sees a desire, on the part of museum audiences, for embodied experience; this desire unquestionably meets an eagerness, on the part of institutions, to package and present those experiences. However, she queries the negative reading of this trend, wanting especially to avoid the "gloomy prognoses" boiling the issue down to the neoliberal exploitation of a precarious, affective labor force (Bishop 2018, 23). She argues that when we look at these works, we might instead attend to how they engender emergent modes of spectatorship, often conspicuously mediated by devices (23). This leads her to stress uncanny moments wherein 
Hassabi's work invites viewers to watch others watching, or not watching-either reaching "automatically" for their phones or stepping blithely over bodies lying prone on walkways and stairs, bodies resembling "lifeless corpses" (32-33).

At MoMA, Hassabi threaded PLASTIC through the museum's transitional spaces (including stairs, passages, lounges, and walkways), avoiding its galleries. Importantly, the portion of the work that I had performed, as well as its tightly cocooned gallery staging, was eliminated. Hassabi's exclusive focus on the museum's public spaces emphasized, as Bishop notes, multiple possibilities for spectatorship, a range spanning careful attention, disregard, and, of course, cell phone documentation. As a performer ensconced within an exhibition space framed by stark theatrical lighting, I experienced a much more tense confrontation than the encounters at MoMA described by Bishop, one in which spectators seemed to feel too involved to document, and too involved to look away. In my experience, Hassabi opened a deep gulf between my presence and that of the spectator; I came to perceive my extreme slowness as heavy and demanding, a contagious thingliness that they seemed desperate to flee. On the rare occasion that someone watched a sustained segment (or even more rarely, the entirety of the loop), I registered heightened tension for a few moments before it felt as if we were both retreating into experiences that did not, and could not, overlap.

As I became object-like in my flirtation with inanimacy, the invitation for scopophilic pleasure triggered, instead, panic. Recalling Yvonne Rainer's famous assertion that "dance is hard to see," we might apply this with a double meaning in the context of Hassabi: hard, as in difficult to discern; and hard, as in difficult to bear ([1966] 1995, 271). While Rainer was addressing the solidification and objectification of movement via strategies such as repetition or simplification, she was also clearly thinking of dance as something that moves too quickly, something that cannot be stilled long enough to be confidently held in perception. Hassabi's sculptural choreographies wink at the difficulty of perceiving movement that is too fast to seize, and then morph into the affront of a body seeming to do very little while demanding attention in its eerie, outward calm. However, there is more to the difficulty: Hassabi's choreography is also hard to see because of the lacuna between the materiality of the dancer's movement registered from the "inside" and its slowly moving presentation for the spectator. Thus, dancer and spectator alike are exposed to a profound dislocation between interiority and exteriority. PLASTIC's overlapping materialities (bodies and movement) withdraw even as they remain available, confrontational whether the spectator engages deeply, blithely passes, or refuses to look. Where Rainer probes objectification strategies that might render movement more accessible, Hassabi explicitly crafts movement that frustrates the viewer's sense of certainty and connection.

The powerful disjoint I registered from within Hassabi's choreography put me in mind of philosopher Graham Harman's discussion of withdrawal as a foundational concept in object-oriented ontology. Harman posits a profound disconnection between an object's interiority and its exteriority, which, in turn, short-circuits the human experience of certainty typically accompanying object instrumentalization. Harman builds a lack of access_-a disruption-into relationality itself, which applies as much to inter-object relationships as to those driven by human needs and desires. "No object," Harman writes, "ever unlocks the entirety of a second object, ever translates it completely literally into its own native tongue" $(2011,223)$. Here, Harman is explicitly responding to Heidegger, whose distinction between things and objects delineates the former as "self-supporting, or independent," and the latter as a "represented," something understood and available to the perceiving subject (1971, 164-165). Although I have moved freely between the terms of "thingliness" and "objecthood" in the course of this analysis, I do find this philosophical distinction useful insofar as it forefronts the capacity for certain materialities (like those associated with PLASTIC) to resist relational union. In line with Heidegger, and perhaps more pertinently to my discussion of PLASTIC, Bill Brown discusses thingness as that which lies "beyond the grid of intelligibility the way mere things lie outside the grid of museal exhibition, outside the order of objects" (2001, 5). As Hassabi's movement things collided with the museum's "order of objects," they remained 


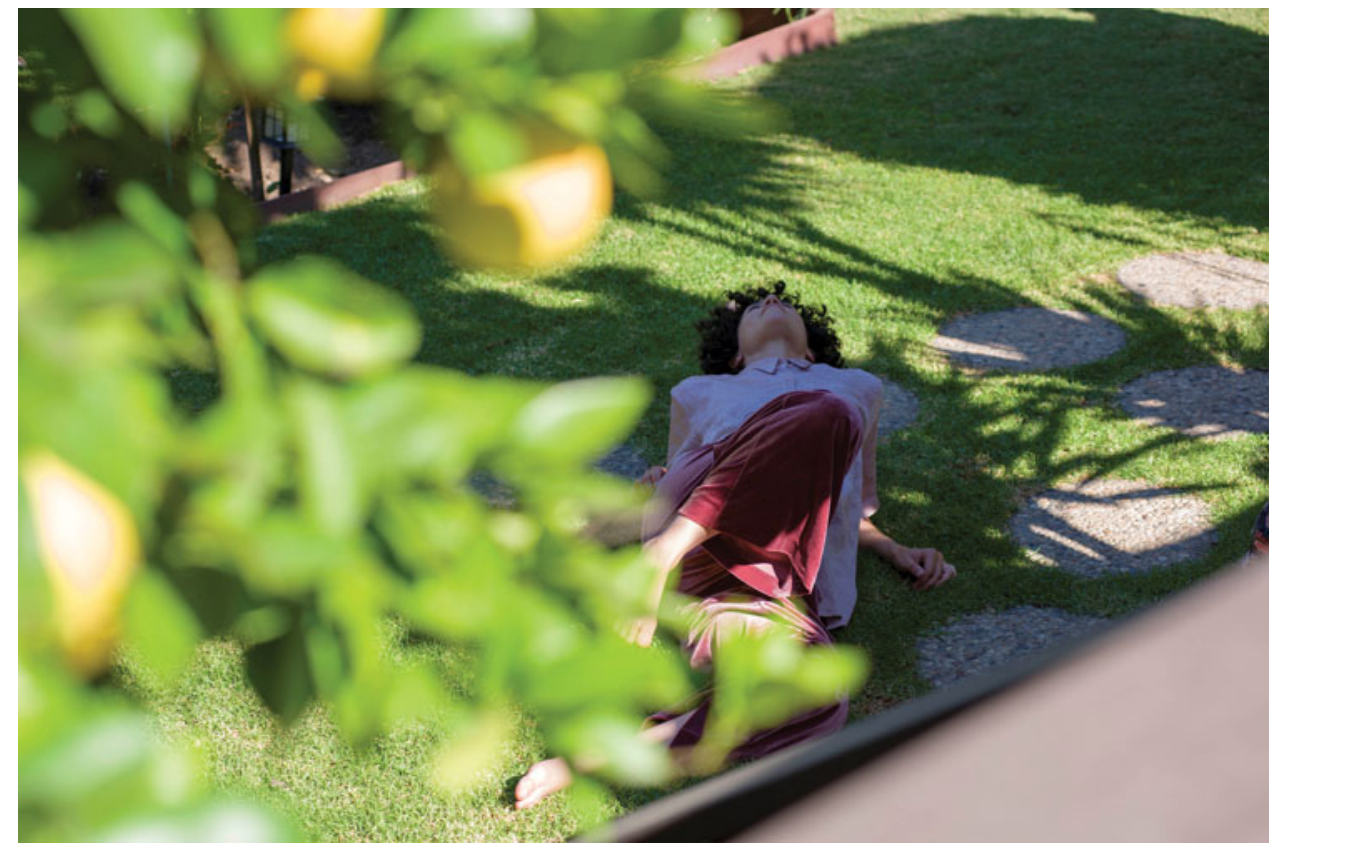

Photo 3. Rebecca Bruno practicing The Sacred Something in Where Do We Meet?, presented by HomelA, 2018. Photo by Ruben Diaz.

uncomfortably impenetrable, unavailable to spectators in a provocatively alienating way, drawing the availability of the museum's less "thingly" objects into question as well.

\section{Vibrant Clutter and the Decentered Subject}

Dancing PLASTIC, I felt myself vacillating between perceptibility and imperceptibility, hyperconscious of the way in which the dance frustrated my own desire to embody and perform availability. In The Sacred Something, by contrast, I took spectatorship out of the equation, dancing alone and applying virtually no choreographic structure, intentionally exploring movement landscapes far more cluttered than those of PLASTIC or Huddle. As an early impetus, I wanted to question the dancing body's tendency to command a field of perception, to draw the unresolvable complexity of environmental landscapes into sharp, singular points of focus. I aimed to dance among things without asking for anything from them, without recruiting my environment into the compositional field over which I had been trained to wield control. I danced in order to sink back into my environment rather than to foreground myself, and to imagine embeddedness beyond hierarchies in which I inevitably played out an experience of my own "centeredness." Without being fully aware of it at the time, I was playing at the impossible task of improvising while sidelining my own subjectivity, forging a relationship with my movement that displaced myself as its origin.

These goals, as I suggest, opposed much of my training. As a young dancer, I explored various methods of improvisation that fostered an acute facility for decision-making and specific tools for relating to environments. This included Viewpoints, for example, a systematic, ensemble-driven method of improvisation and composition developed by the choreographer Mary Overlie and subsequently adapted by theater director Anne Bogart. Viewpoints introduces a set of clear foci for performer awareness, designed to organize spontaneous action with respect to various spatial and 
temporal possibilities. A guide to the practice illustrates how performers might turn their attention to, for example, architecture:

The floor beneath your feet. Shift your awareness to the architecture which is already there, with which you are already working (albeit probably unconsciously). We always, in in some way large or small, position ourselves in relation to mass: to walls, objects we sit in or stand near or far from, posts we lean on, tables we rest on, space we center ourselves in or find the corners of, etc. (Bogart and Landau $2005,52)$

Settling into these prompts, performers might register for the first time the presence of an accompanist's piano in the corner, the windows that can be used to "frame" bodies, or the height of a ceiling creating more or less potential for verticality. All of these become potential triggers or reference points for action, source materials for spontaneous composition. I have found systems like this immensely valuable, and I wanted to retain an awareness of the environment in which I danced. I was also, however, looking to shift my relationship to the things within and around me (not only pianos, windows, floors, and ceilings but beams of light, gusts of wind, memories, habits, and desires), trying to accept and expand that awareness without succumbing to the pull of "working with it."

I also wanted to explore perceptually cluttered spaces, letting my movement reside amid things rather than unspooling on an assiduously emptied terrain. Following James Gibson, I was looking for a sense of plenum, or, "filled" space (Mace 2014, xviii). I was likewise informed by Harmony Bench's theorization of no-places, visual fields where "bodies wander through space with an illusory freedom, unrestricted by physical or ideological barriers" $(2008,37)$. Bench focuses on the digital sphere, but the physical spaces (studios, theaters, galleries) that host so much of our dancing also reflect an ideal of unhampered movement, serving as blank geographies foregrounding the dilated presence of the dancer. Bench demonstrates how the urge to clear space for dance exhibits remarkable continuity from the planimetric, eighteenth-century notations of Feuillet to the development of computer programs designed to "envelop dancers in a void" (40). By contrast, what might a dance of hyper-locatedness look like, especially one not leveraging that locatedness into compositional acuity? How, in an utterly practical manner, might one celebrate the abundance and specificity of things in particular while resisting the urge to manage their appearance within a unified compositional field?

In a surprising and moving account of the neurodivergent experience, Erin Manning and Brian Massumi theorize a "dance of attention" that radically decenters neurotypical responses to physical environments (2014). They cite autistic writers, as well as autism researchers and advocates to tease out a "mode of existence" hinging on deep, multisensory immersion in a highly "textured" environmental field-one in which the subject is not necessarily "the maker of the scene" (4-6). Although these personal accounts often describe stimuli reaching an overwhelming level (perceptual situations getting "out of control") they also demonstrate that, from the embodied experience of autism, heightened sensitivity does not necessarily register as a deficit or pathology (13). These accounts allowed me to find my way into what I call "the overwhelm," a pleasurably saturated state in which things (both seen and unseen) became monumental, and my own body succumbed to a destabilized sense of scale.

Intentionally courting the overwhelm, I welcomed the perceptual shock of seeing this blade of grass in almost painful detail while retaining an awareness of the many others surrounding it, some of them touching me and thus providing additional constellations of impact. Allowing myself to swim in the overwhelm helped me edge away from privileging my own experience; the things I encountered became too autonomous to be used for any particular compositional purpose. Such a perceptual orientation encouraged me to locate my dancing within the flooding cacophony 
of the world around me, helped me ride the tumbling continuity of my awareness even as it submerged itself in the magnitude of everything else. (My awareness may be the only vantage point I have, but it is nonetheless one that can undermine itself ever so slightly by imagining the presence of other centers.) As I took up Manning and Massumi's invitation to slide into an "attentiveness of the environment to its own flowering," I was alert to the problematic possibility of borrowing, or instrumentalizing, facets of the neurodivergent experience $(2014,6)$. By no means intending to represent or reproduce that experience, I was nonetheless provoked by their account of its generativity. This inclusive theoretical approach to perception and environmental awareness encouraged me to consider how I might cultivate a less hierarchical sense of inclusion within an impossibly complex field.

Because of the perceptual excess, it was difficult, not surprisingly, to dance. As I sat in the small, terraced yard behind my house, I eased into a bifurcated sense of myself as subject and object, perceiving entity and entity perceived. From there, I explored a more imaginary, speculative mode, probing the edges of all that was irreducible to my consciousness. I shifted from an awareness of horizontality to a wonderment about verticality, acknowledging the unseen strata of soil and rock below, the vastness of atmospheric layers above. Resisting the urge to clarify my experience with compositional choices, I struggled to release myself from the pull of representing my environment through movement. If there was a tree moving in my field of vision, how to be with its dance without replicating it, making it my own? I was aware of the breakneck pace of my own attention, my mind darting from one stimulus to another. I realized that this quickness could likewise be acknowledged without finding representation in movement. As I got more practiced at this mode of improvisation, I found it immensely relaxing, a way of moving through the world unburdened of the need for mastery or management.

Beyond what surrounded me, the various materialities of my "interior" also commanded attention in their jostling multiplicity (organs, limbs, physical sensations, impulses, habits, self-judgments, etc.). Producing movement began to feel almost gratuitous as existing materials inside and outside my body piled up in my awareness. It took some time to accept the desire to dance, if it was present, as just another "thing" deserving of attention. As dancing proceeded, I introduced the idea that I could move as if I were placing self-contained entities into my environment: a shift of weight, a gesture of the arm, a careening run to the edge of a concrete wall. Much later, after teaching The Sacred Something in a workshop setting, one of the participants reported a not unpleasant sense of heaviness resulting from this prompt. That feeling differs quite sharply from the common, and often implicit, association of movement with flow, ceaseless passing, or perpetual, always incomplete, becoming (LaMothe 2015, 33). Yet movement things did pile up, dropping like leaves off a tree. They butted up against everything else that was present; they appeared, reappeared, transformed, and joined forces. I told myself to affirm everything as real, even if certain things seemed ghostly, even if they could not be named. Give things space, I urged myself, but do not apply pressure toward their enactment. Causality and relationality were present but de-emphasized. Finding myself near that concrete wall, for example, I stopped: the relationship between myself and the wall was less important than the wholeness of the new situation, rich with specificity (D'Amato 2019).

The fullness of these explorations strained against the bounds of how I understood movement mattering, in every sense of the word. If I was not under pressure to make interesting choices, if my habits were just as valid as what felt fresh, and if my impulses had integrity whether or not I obeyed them, then how was this prolific accumulation conceptually distinct from dancing as disappearance? That is, dancing with the sheer abundance of things that I worked so hard not to hierarchize, how could anything truly materialize? The notion of sacredness struck me as an antidote to this confounding weightlessness. Everything that I encountered (vast or tiny, interior or exterior, visible or invisible) astonished me with its capacity to be this thing, hallowed without being special. I realized that it was unsurprising to end up at a sense of thingly sanctity after following the braided physical and conceptual paths I have been describing. As theorist Andrew Cole suggests in a critique 
of object-oriented ontologies: "Contradictions within each of these new philosophies ... can be resolved, I suggest, when the idealism and mysticism of these fields are acknowledged rather than disavowed" $(2013,107)$. He attends to the antecedents of contemporary materialism in premodern, and often medieval, thought, questioning the extent to which twenty-first-century materialisms evidence a wariness of anything in the thrall of quasi-religious materialist ontologies, also sometimes referred to as "naively representational or naturalistic" (Coole and Frost 2010, 3).

Indeed, in her influential treatment of "vibrant matter," Jane Bennett cautions that the potent vitality of nonhuman actants need not be "experienced or conceived as partaking in divinity or purposiveness" $(2010,93)$. She dwells on trash and detritus, making a particularly powerful example of the collection of objects found one morning in a Baltimore storm drain: a work glove, a "mat" of oak pollen, a dead rat, a bottle cap, and a stick (4). For Bennett, these objects "shimmied back and forth between debris and thing," tossed away but nonetheless powerful (4). It is this paradoxical power that, for me, dismantled the conceptual opposition between junk and sanctity. The Sacred Something embraces specificity while refuting purity, eschewing any theatrical or compositional controls designed to limit detritus. In dance studios now, in fact, I find my gaze drawn to the edges: belongings bursting messily out of tote bags, the objects straddling our everyday and dancing lives. My imagination drifts to the movements deemed extraneous to finished dances, the material worlds crowding in at the edges. What possibilities for care and sustenance might be found among these scraps and piles of junk: stuff that is sacred but not important, extraneous to the dances that end up packaged and commodified, even as they are touted as fleeting and immaterial?

\section{New and Belated: Movements of Theory}

As I hope to have suggested, Huddle, PLASTIC, and The Sacred Something invite not only a profound reconsideration of movement's relationship to ephemerality, but also a profound reorientation of movement's relationship to dancerly self-possession and self-expression. Again, I do not see this as a firm ontological stance so much as a playful and provisional one, one that incidentally disrupts the ideal of movement pouring forth from a sovereign and well-contained dancing subject. In wresting movement from its all-consuming relation to the performing subject, perhaps we let movement take up a new kind of space in the world. We also, perhaps, establish new theoretical grounding for dances asserting clear agency across uncommonly long and complex life spans (Huddle), dances engendering perplexing and resistive modes of relationality (PLASTIC), and movement practices establishing choreographic parameters while eluding compositional shaping (The Sacred Something).

Even as I have argued, however, that new materialisms open up potentially productive theoretical and critical pathways for dance studies, I am uncomfortably aware of how seizing too firmly on conceptual frameworks can fail to do justice to the very practices we mean to affirm. I am wary of the tendency to use dancing bodies to "mannequin" theories, as well as the temptation to deploy theory in the ongoing quest to legitimize embodied praxis as a form of knowledge production (Cvejić $2015,12)$. As a practitioner, I have no stake in any particular theory's recourse to truth, but I do invest in any and all theoretical possibilities that seem corporeally provocative. As a researcher enmeshed in both practice and theory, I am especially interested in the degree to which embodied experimentation urges constant reappraisal of the discourses used to contextualize it.

I also question the validity of my own starting point at the threshold of "new" materialisms. Writing in 2021, I arrive at the conversation somewhat belatedly in the context of their early twenty-first-century resurgence. Already in 2001, though, Bill Brown brooked accusations of "thing theory" being passé, linked to a preoccupation of the 1990s that recapitulated "surrealism's materialist bricolage" of the 1920s $(2001,13)$. Even more pertinent than anxieties about dawdling in a theoretical moment that seems always to be passing, however, are the reminders that the lifeways 
and knowledge systems affirming nonhuman agency have been some of the most conspicuous targets of settler colonialism. As Chickasaw writer and scholar Linda Hogan points out, to "those who have always prayed with, to, and for the waters, and known our intimate relatives, the plant people, the animals, insects, and all our special relations, the field of animism is a belated study" (2013, 17). ${ }^{13}$ I dive into this belated project, in part, to resist the way in which collective shifts in thought often cannibalize what has come before. The "linguistic turn" (as well as the phenomenological perspectives) so vilified by object-oriented philosophy, for example, have been and continue to be incredibly generative for dance studies. Ultimately, disciplines that maintain a firm footing in embodied practice, such as dance, demonstrate more clearly than most how the movement of ideas can proceed without necessitating the wholesale repudiation of their predecessors.

Looking back over ten years of physical practice, I find it inherently provocative to toy with these theories even as they threaten to overwhelm the body's preference for possibility and promise over certainty, even as they may already be part of a theoretical wave that passed. Because I dip into various literatures without declaring allegiance to any one of them, I see this as a choreographic approach rather than a philosophical one-one that allows belatedness, sudden stops, contradictions, and changes of direction. While undertaking this research, I paged through a copy of Heidegger's Being and Time (1927), saved from my undergraduate studies. In an essay titled "On the Origin of the Work of Art," I found a note penciled in beside Heidegger's declarative statement about all artworks having a "thingly character" (1993, 145). In all caps, I defiantly scrawled, "NO THEY DON'T.” Newly exposed to both Western philosophy and dance studies, I was reacting to Heidegger's categorical exclusion of dance as he enumerated the thingly qualities of various creative disciplines. ${ }^{14}$ In retrospect, it is clear that I was annoyed but also energized by the philosophical uniqueness of dance, the confounding ontological nature that has often led to its marginalization. Though my consideration of kinetic materiality has evolved, this special identity still excites methe way in which dance can be at home at the (perhaps belated) horizon of a ragged movement of thought, barely fitting in, its substance and heft most readily discernible from the interiors of a practice.

\section{Notes}

1. For a helpful summary of the ways in which new materialisms emerge, in part, from the "exhaustion of once popular materialist approaches, such as existential phenomenology or structural Marxism," and "the important challenges by poststructuralists to the ontological and epistemological presumptions that have supported modern approaches to the material world," see Coole and Frost $(2010,3)$.

2. Existing resources on the relationship between performance and new materialisms include a recent Brown University Consortium Issue of $T D R$, with introductory remarks by Rebecca Schneider (2015). In a more dance-specific turn, André Lepecki makes brief mention of new materialisms in his "political and performative theory of things" $(2016,20)$. Although he does not draw substantively on the literature that I have outlined, citing an aversion to the "ontophenomenological drive" of object-oriented philosophies, he does engage with the work of Bruno Latour insofar as it pertains to nonhuman actants (36). For a wholehearted embrace of new materialist perspectives, and a discussion of their implications in practice-based dance research, see Kramer (2012).

3. For detailed analyses of the proliferation of early dance manuals, and their relationship to anxiety about dance's disappearance, see Foster (2011) and Lepecki (2006).

4. Here, I refer to influential projects by André Lepecki (2010), Diana Taylor (2003), José Esteban Muñoz (1996), and others.

5. Nor is the body the only stuff in question. Since at least 1990, William Forsythe has been using the term "choreographic objects" to encompass a surprising variety of initiatives, the first of which involved the "training" of fifty trees to grow in an arc over a Dutch canal for a municipal 
project organized by the architect Daniel Libeskind (Neri and Respini 2018, 30). Then, in 2009, came Synchronous Objects, an ambitious web project that culled "data" from Forsythe's enormously complex One Flat Thing, reproduced (2000), translating that data into interactive "objects" designed to manifest the dance's "physical thinking" outside of (and alongside) the bodies of performers (Zuniga Shaw 2011). Forsythe's more recent choreographic objects go still further to materialize dance outside of the human body. Black Flags (2014), for example, is a sweeping duet for two robotic arms and billowing mass of black fabric. In Towards the Diagnostic Gaze (2013), a readymade feather duster sits next to the impossible choreographic instruction: "Hold the object absolutely still" (Neri and Respini 2018, 147).

6. For a comprehensive assessment of dance as commodity, see Foster (2019).

7. "Designated teachers" of Huddle attest to the quotidian tone preferred by Forti, which can be challenging to achieve as performers fight the "tendency to over-perform, strike poses, and add flourishes" (Wagley 2018).

8. The full title of this compilation is An Anthology of Chance Operations, Indeterminacy, Concept Art Anti-Art, Meaningless Work, Natural Disasters, Stories, Poetry, Essays, Diagrams, Music, Dance Constructions, Plans of Action, Mathematics, Compositions (Young and Mac Low 1963). I will hereafter refer to the volume as An Anthology. In addition to a brief description of Huddle, Forti includes two "dance reports," a description of the dance construction titled Slant Board and a score for two performers titled Instructions for a Dance.

9. The iteration of Huddle that I discuss in this analysis was, in many ways, occasioned by the acquisition itself. I participated in the "First Complete Presentation of Dance Constructions, 1961," presented by The Box Gallery in August 2011. The video footage documenting Forti's teaching of the material is now a part of MoMA's collection.

10. Carrie Lambert asks, for example, whether Huddle is performed or displayed, noting that "though audiences have watched Huddle onstage, they have also seen it in sculpture gardens... Like an object, it is there to be circled, departed from, or returned to at one's will" $(2004,105)$. See also Chave (2000) and Spivey (2009).

11. See Bell (2014) and Gray (2015).

12. Discussing Hassabi's PREMIERE (2013), performance theorist Victoria Gray mentions the significant number of audience members who walked out of the theater well into the dance's eighty-three-minute duration. Over the course of the performance, dancers carefully executed a 180-degree turn, once again embodying a slow kinetic materiality at the threshold of the imperceptible. Gray describes the extreme slowness as confrontational, a threat to dance's hyperkinetic ontology and a "problem" for the spectator $(2015,156)$. She goes on to emphasize, though, that the bodies of PREMIERE were "not inert," that the frequent misattribution of stillness to Hassabi's work arises due to her knack for troubling "easy binaries between animate and inanimate, still and moving states" $(152,154)$.

13. For additional perspectives addressing the rhetorical attribution of "newness" within the field of new materialism, see Coole and Frost (2010, 4) and Tompkins (2016).

14. Heidegger writes: "Even the much-vaunted aesthetic experience cannot get around the thingly aspect of the artwork. There is something stony in a work of architecture, wooden in a carving, colored in a painting, spoken in a linguistic work, sonorous in a musical composition" (1993, 145). Though this enumeration of thingly qualities excludes dance, it is not hard to see how Heidegger's attribution of "thingliness" to aspects like speech and sonority (not conventionally considered material) could be extended to movement.

\section{Works Cited}

Bakst, Lauren. 2017. "Lauren Bakst: To Huddle.” Danspace Project Journal, no. 5 (Winter-Spring). February 7. Accessed March 15, 2021. https://danspaceproject.org/2017/02/07/lauren-bakst-to-huddle/.

Barad, Karen. 2007. Meeting the Universe Halfway: Quantum Physics and the Entanglement of Matter and Meaning. Durham, NC: Duke University Press. 
Bell, Biba. 2014. "Slow Work: Dance's Temporal Effort in the Visual Sphere." Performance Research 19 (3): 129-134.

Bench, Harmony. 2008. "Media and the No-Place of Dance." Forum Modernes Theater 23 (1): 37-47. Bennett, Jane. 2010. Vibrant Matter: A Political Ecology of Things. Durham, NC: Duke University Press.

Bishop, Claire. 2018. "Black Box, White Cube, Gray Zone: Dance Exhibitions and Audience Attention." TDR: The Drama Review 62 (2): 22-42.

Bogart, Anne, and Tina Landau. 2005. The Viewpoints Book: A Practical Guide to Viewpoints and Composition. New York: Theatre Communications Group.

Brown, Bill. 2001. “Thing Theory.” Critical Inquiry 28 (1): 1-22.

Bryant, Levi R. 2011. The Democracy of Objects. Ann Arbor, MI: Open Humanities Press.

Bryant, Levi, Nick Srnicek, and Graham Harman, eds. 2011. The Speculative Turn: Continental Materialism and Realism. Melbourne: re.press.

Chave, Anna C. 2000. "Minimalism and Biography." The Art Bulletin 82 (1): 149-163.

Cole, Andrew. 2013. "The Call of Things: A Critique of Object-Oriented Ontologies.” Minnesota Review 80 (1): 106-118.

Coole, Diana, and Samantha Frost. 2010. New Materialisms: Ontology, Agency, and Politics. Durham, NC: Duke University Press.

Cvejić, Bojana. 2015. "From Odd Encounters to a Prospective Confluence: Dance-Philosophy." Performance Philosophy 1 (1): 7-23.

D’Amato, Alison. 2019. “The Sacred Something." Imagined Theatres, no. 3 (August). Accessed March 15, 2021. https://imaginedtheatres.com/open/.

Forti, Simone. 1991. Interviewed by Anne Kilcoyne in The CNDO Transcripts: Simone Forti. Arts Archives, Arts Documentation Unit, Centre for Arts Research and Development. Exeter, UK: University of Exeter, 4-5. November 23.

Foster, Susan Leigh. 2011. Choreographing Empathy: Kinesthesia in Performance. New York: Routledge.

- 2019. Valuing Dance: Commodities and Gifts in Motion. New York: Oxford University Press.

Franko, Mark. (1993) 2015. Dance as Text: Ideologies of the Baroque Body, rev.ed. New York: Oxford University Press.

— - ed. 2017. The Oxford Handbook of Dance and Reenactment. New York: Oxford University Press.

Fried, Michael. 1998. Art and Objecthood: Essays and Reviews. Chicago: University of Chicago Press.

Gray, Victoria. 2015. "The Choreography of Anticipation in Maria Hassabi's PREMIERE." TDR: The Drama Review 59 (3): 150-157.

Harman, Graham. 2011. Tool-Being: Heidegger and the Metaphysics of Objects. Chicago: Open Court.

Heidegger, Martin. 1971. Poetry, Language, Thought. Translated by Albert Hofstader. New York: Harper \& Row.

—. 1993. Basic Writings: From Being and Time (1927) to The Task of Thinking (1964). New York: HarperCollins.

Hogan, Linda. 2013. "We Call It Tradition.” In The Handbook of Contemporary Animism, edited by Graham Harvey, 17-26. Durham, UK: Acumen Publishing Limited.

Kramer, Paula. 2012. "Bodies, Rivers, Rocks and Trees: Meeting Agentic Materiality in Contemporary Outdoor Dance Practices.” Performance Research 17 (4): 83-91.

Lambert, Carrie. 2004. "More or Less Minimalism: Six Notes on Performance and Visual Art in the 1960s." In A Minimal Future? Art as Object 1958-1968, edited by Ann Goldstein, 103-110. Los Angeles: The Museum of Contemporary Art. Published in conjunction with an exhibition of the same title, organized by and presented at The Museum of Contemporary Art/Los Angeles, March 14, 2018-August 2, 2004.

LaMothe, Kimerer L. 2015. Why We Dance: A Philosophy of Bodily Becoming. New York: Columbia University Press. 
Lepecki, André. 2006. Exhausting Dance: Performance and the Politics of Movement. New York: Routledge.

—. 2010. "The Body as Archive: Will to Re-Enact and the Afterlives of Dances." Dance Research Journal 42 (2): 28-48.

- 2016. Singularities: Dance in the Age of Performance. New York: Routledge.

Leung, Simon. 2018. "Tea for Three Plus One: Conversation with Simone Forti, Steve Paxton, and Yvonne Rainer.” X-TRA 21 (1). Fall. Accessed May 22, 2020. https://www.x-traonline.org/article/ tea-for-three-plus-one-conversation-with-simone-forti-steve-paxton-and-yvonne-rainer/.

Lieber, Molly. 2017. "Molly Lieber on Simone Forti Workshops." Danspace Project Journal, no. 5 (Winter-Spring). February 7. Accessed March 15, 2021. https://danspaceproject.org/2017/02/ 07/molly-lieber-on-simone-forti/.

Lim, Nancy. 2016. "MoMA Collects: Simone Forti's Dance Constructions." Inside/Out: A MoMA/ MoMA PS1 Blog. January 27. Accessed October 18, 2021. https://www.moma.org/explore/inside_out/2016/01/27/moma-collects-simone-fortis-dance-constructions/.

Mace, William M. 2014. Introduction to The Ecological Approach to Visual Perception, by James J. Gibson, xvii-xxix. Psychology Press Classic Editions. New York: Psychology Press (Taylor \& Francis Group).

Manning, Erin, and Brian Massumi. 2014. Thought in the Act: Passages in the Ecology of Experience. Minneapolis: University of Minnesota Press.

Meillassoux, Quentin. 2008. After Finitude: An Essay on the Necessity of Contingency. London: Continuum.

Metcalf, Megan G. 2018. "In the New Body: Simone Forti's Dance Constructions (1960-61) and Their Acquisition by the Museum of Modern Art (MoMA)." PhD diss., University of California: Los Angeles.

Morse, Meredith. 2016. Soft Is Fast: Simone Forti in the 1960s and After. Cambridge, MA: MIT Press. Morton, Timothy. 2011. "Here Comes Everything: The Promise of Object-Oriented Ontology." Qui Parle: Critical Humanities and Social Sciences 19 (2): 163-190.

Muñoz, José Esteban. 1996. "Ephemera as Evidence: Introductory Notes to Queer Acts.” Women \& Performance: A Journal of Feminist Theory 8 (2): 5-16.

Neri, Louise, and Eva Respini, eds. 2018. William Forsythe: Choreographic Objects. Boston: The Institute of Contemporary Art/Boston and DelMonico Books. Published in conjunction with an exhibition of the same title, organized by and presented at The Institute of Contemporary Art/Boston, October 31, 2018-February 24, 2019.

Povinelli, Elizabeth A. 2016. Geontologies: A Requiem to Late Liberalism. Durham, NC: Duke University Press.

Rainer, Yvonne. (1966) 1995. “A Quasi Survey of Some 'Minimalist' Tendencies in the Quantitatively Minimal Dance Activity Midst the Plethora, or an Analysis of Trio A." In Minimal Art: A Critical Anthology, edited by Gregory Battcock, 263-273. Berkeley: University of California Press.

Santos-Granero, Fernando. 2009. The Occult Life of Things: Native Amazonian Theories of Materiality and Personhood. Tucson: The University of Arizona Press.

Schneider, Rebecca. 2011. Performing Remains: Art and War in Times of Theatrical Reenactment. New York: Routledge.

—. 2015. "New Materialisms and Performance Studies." TDR: The Drama Review 59 (4): 7-17. Sheets-Johnstone, Maxine. 2015. The Phenomenology of Dance. Philadelphia: Temple University Press.

Spivey, Virginia B. 2009. “The Minimal Presence of Simone Forti." Woman's Art Journal 30 (1): $11-18$.

Taylor, Diana. 2003. The Archive and the Repertoire: Performing Cultural Memory in the Americas. Durham, NC: Duke University Press.

Tompkins, Kyla Wazana. 2016. "On the Limits and Promise of New Materialist Philosophy." Lateral, no. 5.1 (Spring). Accessed March 15, 2021. https://doi.org/10.25158/L5.1.8. 
Wagley, Catherine. 2018. "How MoMA Rewrote the Rules to Collect Choreographer Simone Forti's Convention-Defying 'Dance Constructions." Artnet News, September 19. Accessed May 22, 2020. https://news.artnet.com/exhibitions/moma-rewrote-rules-collect-choreographer-simone-fortisconvention-defying-dance-constructions-1350626.

Young, La Monte, and Jackson Mac Low, eds. 1963. An Anthology of Chance Operations, Indeterminacy, Concept Art Anti-Art, Meaningless Work, Natural Disasters, Stories, Poetry, Essays, Diagrams, Music, Dance Constructions, Plans of Action, Mathematics, Compositions. New York: La Monte Young and Jackson Mac Low. , eds. 1965. "Lecture 1960." The Tulane Drama Review 10 (2): 73-83.

Zuniga Shaw, Nora. 2011. "Synchronous Objects, Choreographic Objects, and the Translation of Dancing Ideas." In Emerging Bodies: The Performance of Worldmaking in Dance and Choreography, edited by Gabriele Klein and Sandra Noeth, 207-224. Bielefeld: transcript-Verlag. 